\title{
Duration of unspecific prodromal and clinical high risk states, and early help-seeking in first-admission psychosis patients
}

\author{
Frauke Schultze-Lutter ${ }^{1} \cdot$ Jonas Rahman $^{1} \cdot$ Stephan Ruhrmann $^{2} \cdot$ Chantal Michel $^{1}$ \\ Benno G. Schimmelmann ${ }^{1} \cdot$ Wolfgang Maier $^{3} \cdot$ Joachim Klosterkötter ${ }^{2}$
}

Received: 22 April 2015/ Accepted: 29 June 2015/Published online: 9 July 2015

(c) Springer-Verlag Berlin Heidelberg 2015

\begin{abstract}
Purpose Prevention of psychosis requires both presence of clinical high risk (CHR) criteria and early help-seeking. Previous retrospective studies of the duration of untreated illness (i.e. prodrome plus psychosis) did not distinguish between prodromal states with and without CHR symptoms. Therefore, we examined the occurrence of CHR symptoms and first help-seeking, thereby considering effects of age at illness-onset.

Methods Adult patients first admitted for psychosis $(n=126)$ were retrospectively assessed for early course of illness and characteristics of first help-seeking.

Results One-hundred and nine patients reported a prodrome, 58 with CHR symptoms. In patients with an early illness-onset before age $18(n=45)$, duration of both illness and psychosis were elongated, and CHR symptoms more frequent (68.9 vs. $33.3 \%$ ) compared to those with adult illness-onset. Only 29 patients reported help-seeking in the prodrome; this was mainly self-initiated, especially in patients with an early illness-onset. After the onset of first psychotic symptoms, help-seeking was mainly initiated by others. State- and age-independently, mental health professionals were the main first point-of-call $(54.0 \%)$.
\end{abstract}

F. Schultze-Lutter and J. Rahman are first co-authors.

Frauke Schultze-Lutter

frauke.schultze-lutter@kjp.unibe.ch

1 University Hospital of Child and Adolescent Psychiatry, University of Bern, Bolligenstrasse 111, Haus A, 3000 Bern 60, Switzerland

2 Department of Psychiatry and Psychotherapy, University of Cologne, Cologne, Germany

3 Department of Psychiatry and Psychotherapy, University of Bonn, Bonn, Germany
Conclusions Adult first-admission psychosis patients with an early, insidious onset of symptoms before age 18 were more likely to recall CHR symptoms as part of their prodrome. According to current psychosis-risk criteria, these CHR symptoms, in principle, would have allowed the early detection of psychosis. Furthermore, compared to patients with an adult illness-onset, patients with an early illness-onset were also more likely to seek help on their own account. Thus, future awareness strategies to improve CHR detection might be primarily related to young persons and self-perceived subtle symptoms.

Keywords Psychoses - First episode - Early intervention . Health behaviour - Child and adolescent psychiatry

\section{Introduction}

Despite progress in treatment, psychoses often remain chronic, debilitating disorders putting tremendous burden on patients, their families and society [1]. Independent predictors of an unfavourable course are the often lengthy durations of untreated psychosis (DUP) and of untreated illness (DUI), i.e. of both untreated psychosis and its prodromal phase [2-5]. DUP and DUI were reported to be even more extended in early-onset psychosis with a psychosis onset before age 18; yet, this likely represents an epiphenomenon of factors underlying the generally worse prognosis of early-onset compared to adult-onset psychosis $[6,7]$. Within the past two decades, research has focussed on ways to reduce DUP and DUI, i.e. to detect the illness as early as possible to improve its prognosis or even to prevent the onset of a first episode [8,9]. To this aim, however, it is important to examine help-seeking behaviour and pathways-to-care to improve them. 
A recent review on help-seeking and pathways-to-care before the first diagnosis and treatment of a psychotic disorder identified 25 studies (only six of them of the DUI) on altogether 4612 first-episode patients [10]: across these studies, the median DUP was more than one year (60 weeks; range 16-130 weeks), the median DUI was almost four years (203 weeks; range 66-310 weeks), and the average number of help-seeking contacts prior to the initiation of adequate treatment was three. Factors delaying adequate help included sociodemographic and patient characteristics as well as features of the social environment (such as a weak social network) and features of the prodromal and early psychotic state (such as an early onset) [10]. Further, studies of the DUP consistently reported that help-seeking was mainly initiated by family members or friends/colleagues of the patient and only to a lesser extent initiated by patients themselves [11-13].

Studies of the DUI and help-seeking in the prodromal phase are not only fewer than DUP studies, but also lack a differentiation between a prodromal state in that symptoms of clinical high risk (CHR) criteria as currently used in the early detection of psychoses are missing and a prodromal state in that CHR symptoms is present. Because any preventive efforts that specifically aim for a reduction of the risk of developing a first psychotic episode can only be initiated once this risk has been recognized, i.e. once CHR criteria have been detected, such a distinction is important in the evaluation of the timing of help-seeking and adequate treatment. Currently, CHR criteria are mainly defined by attenuated psychotic symptoms and cognitive and perceptive basic symptoms [9]; and before their occurrence, a prodrome or rather CHR of psychosis would not be recognizable. Yet, studies on the DUI generally consider the whole interval from onset of the first mental problem to antipsychotic treatment as a delay in treatment, irrespective of whether or not a beginning psychosis could have been detected-and specifically treated-throughout this time.

Some recent studies, however, have explicitly examined pathways-to-care in early detection services, i.e. helpseeking in patients fulfilling criteria for a CHR [14-21]. Yet, these studies suffer from a general selection bias towards early help-seeking and the unclear diagnostic status of CHR patients with regard to future psychosis. Further, most studies on CHR samples did not distinguish between the onset of unspecific and of CHR symptoms. Only one study on 38 adult CHR patients focused explicitly on the duration of untreated attenuated psychotic symptoms [14] for that a median duration of it of 10.5 months (range 0.07-120) with an average of two contacts to psychiatric services was reported. Similar to first-episode samples, family members held a key role in recommending seeing a psychiatrist in this CHR sample [14], although family involvement in the CHR might be lesser than in first-episode psychosis [15].

\section{Aims of the study}

Extending prior studies, our study on a sample of patients receiving first inpatient treatment for an affective or nonaffective psychosis aimed to differentially assess the frequency and length of the durations of both an untreated unspecific prodromal state without CHR symptoms (DUInoCHR) and an untreated prodromal state with CHR symptoms (DUI-CHR), in addition to the DUP and the total DUI (=DUI-noCHR + DUI-CHR). With regard to earlier findings of longer DUP and DUI in early-onset psychosis, we also examined the potential treatment-delaying effect of an early onset of the illness within childhood and adolescence. Furthermore, the three different states of the illness (DUI-noCHR, DUI-CHR and DUP) were compared for potential differences in type of the main initiator and point-of-call of first help-seeking. We expected that others (incl. family) would be less frequently the main initiators of help-seeking in patients with an adult illness-onset compared to patients with an early illness-onset. Further, we anticipated that others would be less frequently the initiators of help-seeking in the DUI-CHR than in the DUP, and would be least frequently the initiators in the DUI-noCHR. Likewise, mental health professionals were expected to be increasingly the first point-of-call across these three states.

\section{Materials and methods}

\section{Sample}

One-hundred and twenty-eight adult inpatients with firstepisode psychosis were assessed as part of the multi-centre Awareness project of the German Research Network on Schizophrenia [22, 23]. Participation in the study was voluntary and followed informed written consent; the study was approved by the local ethic committees. Patients were interviewed in remission, around the time of discharge. Clinical records were used as a complimentary information source. Two patients did not report on any symptoms prior to their admission and, consequently, were not included in the analyses. Thus, all analyses were based on the remaining 126 patients [23] (Table 1).

\section{Instruments}

Presence and onset of symptoms and of illness states, respectively, were assessed with the "Early Recognition Instrument based on the Instrument for the Retrospective 
Table 1 Sociodemographic and clinical characteristics of the sample $(n=126)$

Total sample

$(n=126 ; 100 \%)$

\begin{tabular}{ll}
\hline Age at admission in years & \\
Mdn (range); mean \pm SD & $29(18-55) ; 30.10 \pm 8.64$ \\
Age at first positive symptom in years & \\
Mdn (range); mean \pm SD & $25(4-51) ; 27.94 \pm 10.42$ \\
Age at first symptom in years & \\
Mdn (range); mean \pm SD & $20(8-50) ; 22.38 \pm 9.78$ \\
Diagnosis at discharge (\%) & \\
Schizophrenia & 88.1 \\
Schizophreniform disorder & 5.6 \\
Schizoaffective disorder & 2.4 \\
Delusional disorder & 0.8 \\
Brief psychotic episode & 3.2 \\
Marital status (\%) & \\
Single & 77.8 \\
Married/living with steady partner & 13.5 \\
Separated/divorced/widowed & 8.7 \\
Current steady partner (\%) & \\
No & 72.2 \\
Level of education (\%) & \\
No certificate/CSE & 35.7 \\
O-level/VBD & 29.4 \\
A-level/still in high school & 34.9 \\
Current occupation (\%) & \\
None & \\
Protected/therapeutic place & \\
Normal occupation & \\
Family history (\%) & \\
No mental disorder known & \\
Psychosis & \\
Other disorder (affective disorders) & $23.8(12.7)$ \\
\hline
\end{tabular}

${ }^{a}$ Clinical diagnosis, not assessed in a standardized manner

b Level of education on leaving school was translated into British school-leaving certificates. CSE Certificate of Secondary Education, $V B D$ vocational baccalaureate diploma. CSE and O levels require 10, VBD 12, and A levels 13 years of schooling, provided that no class had been repeated

c With regard to biological first-degree relatives

Assessment of the Onset of Schizophrenia" (ERIraos) [23, 24] according to the methods used in the Age-BeginningCourse study of schizophrenia [25]. The ERIraos constitutes of 110 symptoms: 70 unspecific and (attenuated) negative symptoms (e.g. increased worrying, depressive mood or sleeping problems), ten cognitive and perceptive basic symptoms included in the CHR criterion 'cognitiveperceptive basic symptoms' [26], five attenuated psychotic symptoms according to the ultra-high risk criteria [27], and
20 psychotic symptoms. Five additional observational items are not applicable in retrospective assessments. Although the ERIraos allows the rating of transient psychotic symptoms according to the ultra-high risk criteria, patients were mainly unable to recall the exact duration of a symptom at certain times in the past and sometimes years back. As a result, in this retrospective study, no distinction between merely transient and more persistent rank psychotic symptoms that would index the onset of the firstpsychotic episode was made.

Initiators and point-of-call of first help-seeking for mental problems were assessed by the 'Pathways-to-Care' questionnaire [28] that had been adapted to the German health care system and slightly modified to account for CHR symptoms.

\section{Early untreated states of psychosis}

In line with many previous studies [10], we used the date of the first admission to hospital for a psychotic disorder as the onset of adequate antipsychotic treatment-although antipsychotic outpatient treatment might have preceded it. Consequently, the DUP was defined as the time between the onset of the first of the 20 psychotic symptoms and the index admission to hospital. The DUI, i.e. DUP plus the prodromal phase of psychosis, was defined as the time between the onset of the first non-psychotic symptom or mental problem and the index admission to hospital.

In extension of earlier studies, the prodromal phase of the DUI was further differentiated as follows: (1) the $d u$ ration of an untreated unspecific prodromal state without CHR symptoms (DUI-noCHR) as the time between the onset of first unspecific symptom and the onset of either the first CHR symptom (attenuated psychotic symptoms, or cognitive or perceptive basic symptoms) or the first psychotic symptom; and (2) the duration of an untreated more specific prodromal state with CHR symptoms (DUI-CHR) as the time between the onset of the first CHR symptom and the onset of the first psychotic symptom. The following ERIraos items were used to assess CHR symptoms in terms of attenuated psychotic symptoms: magical ideation, ideas of reference, paranoid ideation/mistrust, unusual perceptual experiences, body-related illusions or odd thinking and speech; and CHR symptoms in terms of cognitive-perceptive basic symptoms: thought interference, thought perseveration, thought pressure, thought blockages, disturbance of receptive speech, decreased ability to discriminate between ideas and perception, fantasy and true memories, unstable ideas of reference, derealisation, visual perception disturbances (excl. hypersensitivity to light or blurred vision), acoustic perception disturbances (excl. hypersensitivity to sounds). 


\section{Initiators and point-of-call of first help-seeking}

With regard to the person initiating first help-seeking, we distinguished between whether a need for help was recognized by the patient him-/herself or whether someone else convinced the patient to seek help. This latter category "other persons" included parents as well as partners, siblings, friends, colleagues, neighbours and police.

The point-of-call of first help-seeking was subdivided into four categories: general practitioners, professionals, semi-professionals and other contacts. "Professionals" included registered psychiatrists, neurologists and psychotherapists/psychologists as well as psychiatric hospitals, counselling services for mental problems and social psychiatric institutions and their employees. "Semi-professionals" comprised other medical specialists and outpatient departments of general hospitals. "Other contacts" included the police or jurists, clergy, teacher or telephone and other counselling services not specialized in mental problems.

\section{Data analysis}

Since time data were not normally distributed throughout (Kolmogorov-Smirnov-Z $\leq 1.422, p \geq 0.035$ ), the durations of untreated phases were generally compared by Kruskal-Wallis tests and, in case of significance, by post hoc Mann-Whitney tests. Frequencies were compared by either one-dimensional or $k \times l \chi^{2}$-tests. For the exploratory character of the study, an adjustment for multiple testing was not carried out.

\section{Results}

\section{Frequencies and durations of early untreated states of psychosis}

All 126 patients included in analyses reported both unspecific and positive symptoms and, consequently, provided data on both DUP and total DUI-or, more specifically, DUI-noCHR. One-hundred and one patients $(80.2 \%)$ reported at least any one of the ten basic symptoms and $91(74.2 \%)$ reported at least any one of the five attenuated psychotic symptoms. 81 patients $(64.3 \%)$ reported both types of CHR symptoms, attenuated psychotic and basic symptoms; of these, 27 (33.3\%) dated the onset of basic symptoms before the onset of attenuated psychotic symptoms. A total of 111 patients $(88.1 \%)$ reported at least any one CHR symptom before first admission; yet, $53(42.1 \%)$ dated the onset of the first CHR symptom after the onset of the first (transient) psychotic symptom.
Seventeen patients $(13.5 \%)$ reported a psychotic symptom as first symptom, thus only displaying a psychotic but no prodromal phase of any kind (Fig. 1). Twenty-three patients $(18.3 \%)$ reported a CHR symptom as first symptom. A significant majority of patients reported an onset of illness with a psychosis-unspecific mental complaint $\left(n=86 ; 68.3 \% ; \chi_{(2)}^{2}=69.571, p<0.001\right)$; in $35(27.8 \%)$ patients, such unspecific symptoms were followed by CHR symptoms before psychotic symptoms occurred, while 51 (40.5\%) reported only unspecific complaints but no CHR symptoms (Fig. 1). Thus, a combination of DUI-noCHR and DUP, and a combination of all three states were most frequent, while the combination of DUI-CHR and DUP, and the exclusive report of a DUP without a prodrome were significantly less frequent $\left(\chi_{(3)}^{2}=21.429, p<0.001\right)$.

When comparing these four state-pattern groups for their total DUI and DUP, significant differences showed for both (DUI: $\chi_{(3)}^{2}=18.609, p<0.001$; DUP: $\chi_{(3)}^{2}=8.668$, $p=0.034$ ). Post hoc tests (Table 2 ) indicated a longer DUI in the group with all three states compared to the groups with DUI-noCHR and DUP, and with DUP alone; as well as a longer DUI in those with DUI-CHR and DUP compared to those with DUP alone. Patients exclusively reporting a DUP, however, did not differ in their DUP from patients with DUI-CHR and DUP but had a longer DUP than patients with the combination of DUI-noCHR and DUP and those with all three states.

\section{Time of first help-seeking}

One-hundred and twenty patients $(95.2 \%)$ sought help for mental problems before the first inpatient treatment, yet only a minority $(n=29 ; 23.0 \%)$ did so before the onset of the first positive symptom, i.e. within the prodromal phase $\left(\chi_{(1)}^{2}=36.698, p<0.001\right)$. Thereby, the proportion of patients seeking help within the DUI-noCHR $(n=16$, $55.2 \%)$ and within the DUI-CHR $(n=13,44.8 \%)$ did not differ from each other $\left(\chi_{(1)}^{2}=0.310, p=0.577\right)$.

With regard to the four state-pattern groups (Fig. 1), those reporting all three states reported less first help-seeking as late as in the DUP (62.9\%) than patients of the other groups $\left(78.3-100 \% ; \chi_{(3)}^{2}=14.216, p=0.003\right)$ : five of the 35 patients of the three states group (14.3\%) sought help in the DUI-noCHR and eight (22.9 \%) in the DUI-CHR.

\section{Initiators of help-seeking}

A non-significant majority of help-seeking was initiated by other persons $(n=73 ; 57.9 \%)$; only 53 patients $(42.1 \%)$ reported first help-seeking on their own initiative $\left(\chi_{(1)}^{2}=3.175, p=0.075\right)$. Fifty-six of the 73 other persons (76.7\%) were family members (biological or in-law), predominately parents. 


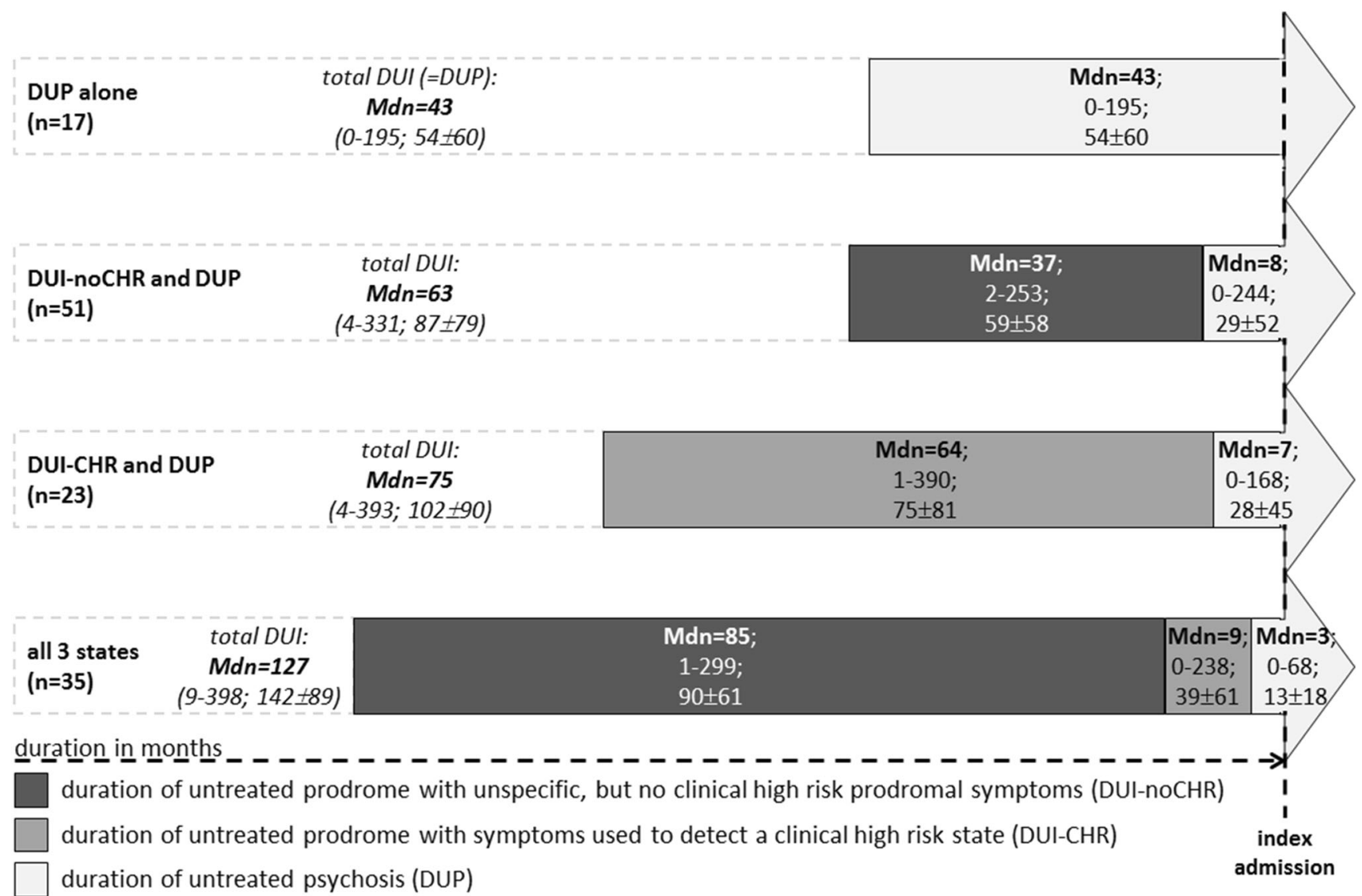

Fig. 1 Frequency, duration, and combination of the early untreated phases of first-episode psychosis $(N=126)$, equating first admission with onset of first antipsychotic treatment. Overall, the median total

Before the onset of the first psychotic symptom, significantly more patients than other persons initiated first helpseeking; while in the DUP, other persons were significantly more frequently the initiators of help-seeking (Fig. 2a; $\left.\chi_{(1)}^{2}=6.186, p=0.013\right)$. Thereby, the role of others in help-seeking became more prominent with increasing severity of symptoms (Fig. 2a; $\chi_{(2)}^{2}=6.840, p=0.033$ ).

\section{Point-of-call of first help-seeking}

Overall, the most frequent point-of-call of first help-seeking was a mental health professional $(n=68 ; 54.0 \%)$. A general practitioner was consulted first by only 21 patients $(16.7 \%)$, semi-professionals by 17 patients $(13.5 \%)$ and other points-of-call by 20 patients $(15.9 \%)$; in half of these cases, the police was contacted.

A general practitioner was significantly more likely contacted in the DUI-CHR (38.5 vs. $18.8 \%$ in DUInoCHR and $13.45 \%$ in DUP; $\left.\chi_{(2)}^{2}=14.813, p<0.001\right)$, and if patients sought help on their own account (Fig. 2b;
DUI was 78.5 months (range: $0-398$; mean \pm SD: $101 \pm 86$ ) and the median DUP 8 months (range: 0-244; mean \pm SD: $28 \pm 46$ )

$\left.\chi_{(1)}^{2}=14.633, p<0.001\right)$. Across all states, a mental health professional was the major first point-of-call (50.0, 46.2 and $55.7 \%$ in DUI-noCHR, DUI-CHR and DUP; $\left.\chi_{(2)}^{2}=0.903, p=0.637\right)$ and significantly more likely contacted first when help-seeking was not self-initiated (Fig. $2 b ; \chi_{(1)}^{2}=5.914, p=0.015$ ). Semi-professionals were never contacted first in the DUI-CHR (vs. $6.3 \%$ in DUI-noCHR and $16.5 \%$ in DUP; $\chi_{(2)}^{2}=18.245$, $p<0.001)$, and contacting them first was not related to type of initiator (Fig. $2 \mathrm{~b} ; \chi_{(1)}^{2}=0.547, p=0.460$ ). Other points-of-call were equally likely to be contacted first across states $(25.0,15.4$ and $14.4 \%$ in DUI-noCHR, DUICHR and DUP; $\left.\chi_{(2)}^{2}=3.750, p=0.153\right)$ or types of initiator (Fig. $2 \mathrm{~b} ; \chi_{(1)}^{2}=0.800, p=0.371$ ).

\section{Influence of age at onset of first mental problems}

At the onset of the first symptom or mental problem, 45 patients $(35.7 \%)$ were younger than 18 years of age: of these, $29(64.4 \%)$ had an onset with an unspecific pro- 
Table 2 Results of post hoc tests of the duration of the different states of untreated illness in the four state-pattern groups (see Fig. 1)

\begin{tabular}{llllr}
\hline Group 1 & Group 2 & Mann-Whitney- $U$ & $Z$ & $p$ (2-tailed) \\
\hline Total duration of untreated & illness (DUI) & & & \\
All 3 states & DUI-noCHR and DUP & 517.0 & -3.301 & 0.001 \\
All 3 states & DUI-CHR and DUP & 281.0 & -1.931 & 0.053 \\
All 3 states & DUP alone & 109.0 & -3.677 & $<0.001$ \\
DUI-CHR and DUP & DUI-noCHR and DUP & 513.5 & -0.853 & 0.394 \\
DUI-CHR and DUP & DUP alone & 117.0 & -2.148 & 0.032 \\
DUI-noCHR and DUP & DUP alone & 301.0 & -1.877 & 0.061 \\
Duration of untreated psychosis (DUP) & DUI-noCHR and DUP & 752.5 & & \\
All 3 states & DUI-CHR and DUP & 346.0 & -1.235 & 0.217 \\
All 3 states & DUP alone & 142.0 & -0.902 & 0.367 \\
All 3 states & DUI-noCHR and DUP & 596.5 & -3.042 & 0.002 \\
DUI-CHR and DUP & DUP alone & 128.0 & -0.199 & 0.842 \\
DUI-CHR and DUP & DUP alone & 289.5 & -1.850 & 0.066 \\
DUI-noCHR and DUP & D & -2.043 & 0.041 \\
\hline
\end{tabular}

All 3 states: patient group reporting unspecific mental problems as first signs of illness, next the occurrence of clinical high risk (CHR) symptoms, and finally that of psychotic symptoms

DUI-noCHR and DUP: patient group reporting unspecific mental problems as first signs of illness and next the occurrence of psychotic symptoms without onset of clinical high risk (CHR) symptoms in-between

DUI-CHR and DUP: patient group reporting clinical high risk (CHR) symptoms as first signs of illness followed by psychotic symptoms and/or unspecific symptoms

DUP alone: patient group reporting an acute onset of psychosis with psychotic symptoms as first signs of illness, unspecific mental problems and/or clinical high risk (CHR) symptoms might have occurred subsequently dromal symptom (only three of them had still been minors when subsequent CHR symptoms occurred) and 13 (28.9\%) an onset with a CHR symptom. Altogether, only nine $(7.1 \%)$ patients had still been younger than age 18 when the first positive symptom occurred, in three $(2.4 \%)$ as the first symptom.

Both total DUI and DUP were significantly longer in those with an early illness-onset before the age of 18 compared to those with an adult illness-onset at age 18 or later (Table 3). Thereby, patients with an early illnessonset reported significantly more frequent a DUI-CHR, with or without a preceding DUI-noCHR, while patients with an adult illness-onset predominately reported an acute onset of psychosis or a DUI-noCHR (Table 3).

At the time of first help-seeking, only seven patients $(5.6 \%)$ were still younger than 18 years of age (three of them with early onset psychosis, four of them had sought help on their own account). Patients with an early and an adult illness-onset did not differ with regard to the time of help-seeking, the initiator of first help-seeking and first point-of-call (Table 3). Yet, equal to the total sample, the early-onset group reported a significantly higher frequency of self-initiated help-seeking before the onset of the first positive symptom, while the adult-onset group reported help-seeking most frequently after the onset of the first psychotic symptom, irrespective of the initiator (Table 3).

\section{Discussion}

This retrospective study on first-admission psychosis inpatients is the first to differentiate between a prodromal phase that, in principle, could have been recognized-and treated-as a CHR state of psychosis and an unspecific prodromal state that could not have been recognized as a beginning psychosis due to the absence of CHR-defining symptoms, i.e. attenuated psychotic symptoms or cognitive-perceptive basic symptoms. Yet, besides this strength, some limitations have to be considered that are often inherent to retrospective assessments [10]. Although the chosen assessment instrument ERIraos allows for the distinction between current transient psychotic symptoms in terms of a CHR state and more persistent psychotic symptoms in terms of an early psychotic state, patients mainly felt unable to give an exact duration of psychotic conviction at different points in the past. As a result, a reliable distinction between transient and frank psychotic symptoms in the past was not possible, and the first incidence of a positive symptom with psychotic conviction was used as the onset of psychosis. Therefore, the rather low $46 \%$-proportion of patients with a CHR state might underestimate the true sensitivity of CHR symptoms-albeit likely only slightly in this respect as transient psychotic symptoms commonly account for only a 
(a) State in that help was first sought ( $n$; \%)

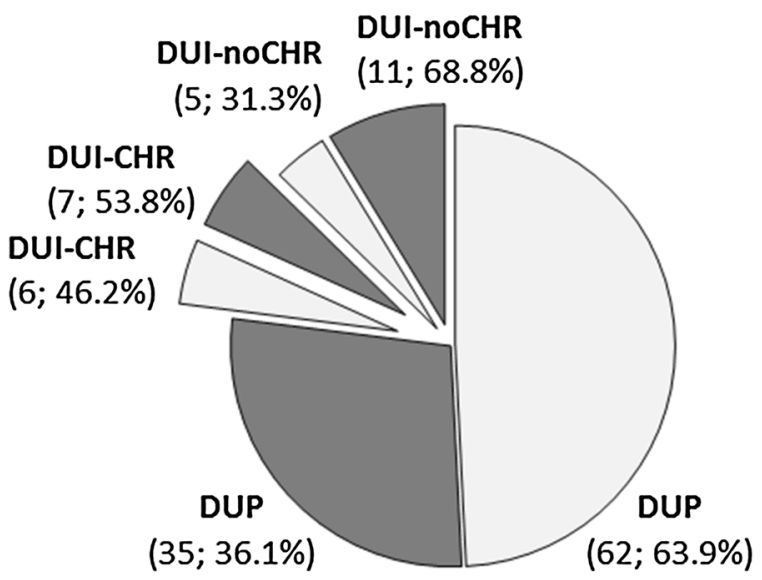

DUI-noCHR: duration of an untreated prodromal state with only unspecific signs/symptoms

DUI-CHR: duration of an untreated prodrome with clinical high risk symptoms

DUP: $\quad$ duration of untreated psychosis (b) Point-of-call of first help-seeking ( $n$; \%)

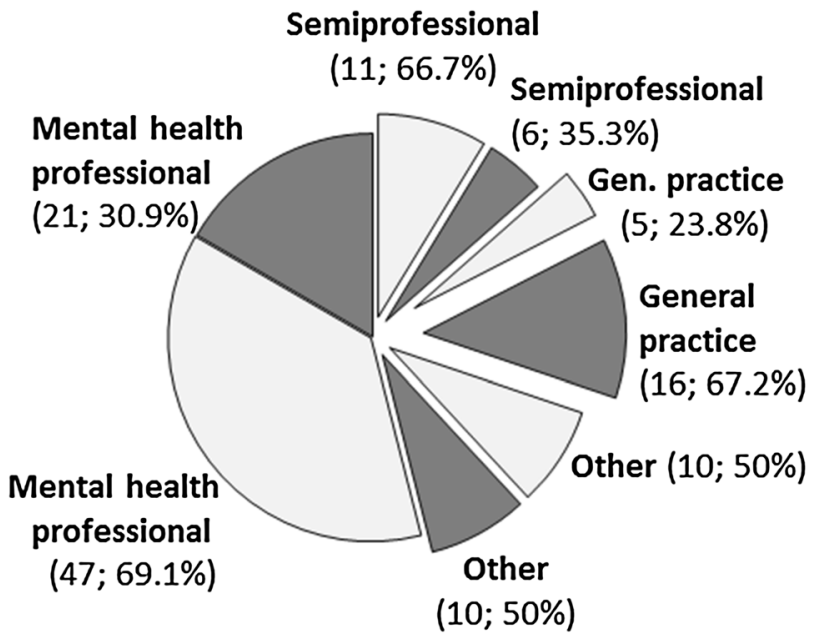

initiation of help-seeking by patient him-/ herself $(n=53)$

initiation of help-seeking by others $(n=73)$

Fig. 2 Proportion of help-seeking on patient's own account and on other's initiative a within the early untreated phases of first-episode psychosis, and $\mathbf{b}$ with regard to the point-of-call of first help-seeking $(N=126)$

minority of inclusions in CHR samples [9, 23, 29]. However, the additional $42 \%$ rate of patients reporting an onset of CHR symptoms after the first occurrence of a psychotic symptom indicates a frequent fluctuation in the severity of symptoms in early psychosis. As already indicated earlier [23], the highest negative impact on the sensitivity of CHR criteria is likely due to a combined recognition-attribution-recall bias, in particular by patients with low education (as a proxy measure of IQ): the retrospective assessment and dating of subtle, not necessarily observable CHR symptoms generally require: (1) spontaneous and highly differentiated symptom recognition by the patient him-/herself at the time of its first occurrence, (2) the attribution of such a recognized symptom as meaningful or important-a prerequisite for storage in long-term memory, and (3) the correct retrieval of the exact symptom and its date of onset from memory. A failure in any one of these three steps will result in underreport of CHR. Thus, considering the high sensitivity of CHR criteria for psychosis reported from helpseeking samples [30-33], likely more patients truly about to develop a psychosis will report CHR symptoms when assessed within the CHR state for present symptoms in a clinical interview and by the help of guiding questions.
Early help-seeking samples, however, will not be representative of psychosis patients, as only a minoritymerely $23 \%$ in our sample-will seek help in the prodromal phase. Another restriction to representativeness is introduced by our choice of a first-admission sample as, in many cases, psychosis patients will only receive outpatient treatment that, in Germany, is mainly provided by psychiatrists working independently in private practice [34]. Thus, our sample is likely biased towards patients with more intense manifestations of the illness who could not be treated as outpatients. However, with regard to the bias introduced by each sampling method, the unbiased sensitivity of CHR criteria can likely be detected only in large longitudinal general population samples using clinical interviews for their assessment $[30,35]$.

A different bias might have been introduced by our choice to equal the onset of adequate treatment to the time of first admission for psychosis. Although not an uncommon cornerstone in the assessment of DUP and DUI [10], potential earlier outpatient diagnosis and treatment of psychosis thus remained unconsidered, thus introducing a bias towards extended durations of untreated illness states. This effect, however, might be counteracted by a participation bias as it was reported that the DUP tended to be 
Table 3 Comparison of patients with an early onset of first symptom before age $18(n=45)$ and with an adult onset $(n=81)$

\begin{tabular}{|c|c|c|c|}
\hline & Early onset & Adult onset & Statistic \\
\hline \multicolumn{4}{|l|}{ Total DUI in months } \\
\hline Mdn (range); mean \pm SD & $156(35-398) ; 165 \pm 90$ & $53(0-331) ; 65 \pm 59$ & $U=562, Z=-6.418, p<0.001$ \\
\hline \multicolumn{4}{|l|}{ DUP in months } \\
\hline Mdn (range); mean \pm SD & $21(0-244) ; 46 \pm 65$ & $5(0-131) ; 17 \pm 27$ & $U=1214, Z=-3.106, p=0.002$ \\
\hline \multicolumn{4}{|l|}{ State patterns $(n, \%)$} \\
\hline DUP alone & $3,6.7$ & $14,17.3$ & $\chi_{(3)}^{2}=14.964, p=0.002$ \\
\hline DUI-noCHR and DUP & $11,24.4$ & $40,49.4$ & \\
\hline DUI-CHR and DUP & $13,28.9$ & $10,12.3$ & \\
\hline All three states & $18,40.0$ & $17,21.0$ & \\
\hline \multicolumn{4}{|l|}{ Help-seeking $(n, \%)$} \\
\hline Before first positive symptom & $13,28.9$ & $16,19.8$ & $\chi_{(1)}^{2}=1.363, p=0.243$ \\
\hline After first positive symptom & $32,71.1$ & $65,80.2$ & \\
\hline \multicolumn{4}{|l|}{ Help-seeking $(n, \%)$} \\
\hline In DUI-noCHR & $7,15.6$ & $9,11.1$ & $\chi_{(2)}^{2}=1.381, p=0.501$ \\
\hline In DUI-CHR & $6,13.3$ & $7,8.6$ & \\
\hline In DUP & $32,71.1$ & $65,80.2$ & \\
\hline \multicolumn{4}{|l|}{ Initiator of help-seeking $(n, \%)$} \\
\hline Patient & $15,33.3$ & $38,46.9$ & $\chi_{(1)}^{2}=2.189, p=0.139$ \\
\hline Other person & $30,66.7$ & $43,53.1$ & \\
\hline \multicolumn{4}{|l|}{ First point-of-call $(n, \%)$} \\
\hline General practitioner (GP) & $9,20.0$ & $12,14.8$ & $\chi_{(3)}^{2}=3.640, p=0.303$ \\
\hline Professionals & $24,53.3$ & $44,54.3$ & \\
\hline Semi-professionals & $3,6.7$ & $14,17.3$ & \\
\hline Other contacts & $9,20.0$ & $11,13.6$ & \\
\hline \multicolumn{4}{|l|}{ Initiator $\times$ help-seeking $(n, \%)$} \\
\hline Patient $\times$ in DUI-noCHR & $5,33.3$ & $6,15.8$ & Early onset: $\chi_{(2)}^{2}=7.212, p=0.027$ \\
\hline Patient $\times$ in DUI-CHR & $3,20.0$ & $4,10.5$ & \\
\hline Patient $\times$ in DUP & $7,46.7$ & $28,73.7$ & Adult onset: $\chi_{(2)}^{2}=2.088, p=0.352$ \\
\hline Other $\times$ in DUI-noCHR & $2,6.7$ & $3,7.0$ & \\
\hline Other $\times$ in DUI-CHR & $3,10.0$ & $3,7.0$ & Total sample: $\chi_{(2)}^{2}=6.840, p=0.033$ \\
\hline Other $x$ in DUP & $25,83.3$ & $37,86.0$ & \\
\hline \multicolumn{4}{|l|}{ Point-of-call $\times$ help-seeking $(n, \%)$} \\
\hline $\mathrm{GP} \times$ in DUI-noCHR & $2,22.2$ & $1,8.3$ & Early onset: $\chi_{(6)}^{2}=2.839, p=0.829$ \\
\hline $\mathrm{GP} \times$ in DUI-CHR & $2,22.2$ & $3,25.0$ & \\
\hline GP $\times$ in DUP & $5,55.6$ & $8,66.7$ & \\
\hline Professional $\times$ in DUI-noCHR & $3,12.5$ & $5,11.4$ & \\
\hline Professional $\times$ in DUI-CHR & $3,12.5$ & $3,6.8$ & Adult onset: $\chi_{(6)}^{2}=6.521, p=0.367$ \\
\hline Professional $\times$ in DUP & $18,75.0$ & $36,81.8$ & \\
\hline Semi-professional $\times$ in DUI-noCHR & 0 & $1,7.1$ & \\
\hline Semi-professional $\times$ in DUI-CHR & 0 & 0 & \\
\hline Semi-professional $\times$ in DUP & 3,100 & $13,92.9$ & Total sample: $\chi_{(6)}^{2}=8.605, p=0.197$ \\
\hline Other $\times$ in DUI-noCHR & $2,22.2$ & $2,18.2$ & \\
\hline Other $\times$ in DUI-CHR & $1,11.1$ & $1,9.1$ & \\
\hline Other $\times$ in DUP & $6,66.7$ & $8,72.7$ & \\
\hline
\end{tabular}

Total DUI: duration of untreated illness (first sign/symptom to index admission)

DUP: duration of untreated psychosis (first psychotic symptom to index admission)

DUI-noCHR: duration of an untreated unspecific prodromal state (first unspecific sign to first clinical high risk or psychotic symptom)

DUI-CHR: duration of an untreated clinical high risk prodromal state (first clinical high risk symptom to first psychotic symptom) 
shorter in participants in early detection studies compared to refusers [36]. Another definition bias might be the distinction of early and adult illness-onset by the traditional 18-year threshold. Recent research indicated that CHR symptoms might actually follow different age thresholds with respect to their prevalence and clinical significance; e.g. attenuated psychotic symptoms seem to follow a 16-year threshold in the community [37].

With these restrictions in mind, our results nevertheless show that, in line with other studies [2, 4, 10], total DUI and DUP are unfavourably long, in particular when the illness has an early onset, and the majority of patients reported a DUP above potentially crucial thresholds for better outcome of between one week to three months [38, 39]. Such a treatment-delaying effect of younger age at onset has already been reported for early-onset psychoses and was related to their poorer prognosis $[6,7,40]$, but also seems to work in adult-onset psychosis with respect to younger age at illness-onset. An early onset of illness also seemed to be related to an insidious onset and the more frequent report of a prodromal phase, in particular of a CHR state. An early insidious development of increasingly more peculiar symptoms (such as CHR symptoms) might have allowed patients to slowly adopt to these changes so that any possible impact on behaviour was subtle enough that others would not start to worry about the patient's mental state. Further, any subtle changes in the young person might have been related to normal peculiarities of adolescence [7]. This might explain why patient's selfinitiated help-seeking in the prodromal phase, in particular the CHR state, was most prominent in those with an early onset. However, in line with earlier studies on initiators of help-seeking [11-15], others, in particular family members, played an important though state-dependent role that became increasingly significant across the early course and with increasing severity, and therewith with increasing likelihood of a behavioural impact of symptoms.

Thus, these findings implicate a stepwise state- and agedependent course of action in awareness programs in the general population that targets on an earlier help-seeking: an insidious onset with subtle and often only self-experienced symptoms incl. CHR symptoms was more likely when the illness started at a young age and was most frequently leading to self-initiated help-seeking. Therefore, an education about subtle, subclinical signs and symptoms that warrant clinical attention at least in terms of clarification or diagnosis should mainly target adolescents, i.e. persons at risk for developing first mental problems, e.g. as part of the school curricula (similar to sex education). Other persons, mainly family members, predominately advised help-seeking when (attenuated) psychotic symptoms had been present. Thus, an education about possible observable correlates of already more severe mental health problems should mainly target adult persons in close contact with the potential to-be patient, in particular parents but also teachers, in general awareness campaigns.

As lack of knowledge regarding the symptoms of psychosis and availability of services were shown to be barriers to help-seeking [41, 42], such campaigns in combination with low-threshold, easily accessible mental health services might reduce the DUP [43]. However, such campaigns - to be efficient-should be a long-term commitment as their effects seem to flatten out as soon as the campaign ends [44].

Reasons for help-seeking, however, might not be related to symptoms relevant for the recognition of a (beginning) psychosis. A recent study in the general population reported that, in young adults reporting CHR symptoms, potential help-seeking occurred for accompanying depressed mood, anxiety and family/partner problems rather than for CHR symptoms themselves, although these were mainly reported as distressing [30, 31]. This highlights the important role of first points-of-call in the early detection of psychosis. In line with other studies from Germanspeaking countries [16, 20, 45-48] of comparable health care systems (both Switzerland and Germany operate according to Bismarck's model with no obligate gatekeeper function of general practitioners [49, 50]), in our study, the most frequent first point-of-call, irrespective of illness state or age at illness-onset, was a mental health professional (in $54 \%$ of cases). Mental health professionals were particularly likely to be contacted first when others and not the patient had initiated help-seeking. First contact with a general practitioner was rather infrequent $(17 \%)$ but most likely in a CHR state (39\%) and when patients sought help on their own account $(30 \%)$. Other medical specialists and outpatient departments of general hospitals played only a minor role as first point-of-call (14\%), particularly in the prodrome. Thus, in particular mental health professionals and general practitioners should routinely probe for CHR symptoms in persons presenting with first or significantly changed mental problems, and their advanced training should prepare them for this. A positive effect of training of general practitioners on identification of CHR symptoms and early psychosis was recently reported [51]. Other medical specialist but also police officers (who accounted for half of "other" points-of-call) might benefit most from an education about psychotic symptoms, as they were almost always contacted only after the onset of first psychotic symptoms.

In summary, our results indicate that detailed knowledge on the prodromal phases and related help-seeking behaviour might facilitate the development of age- and statespecific awareness campaigns that address the specific needs of different target groups and not deliver one message to all. The deliverance of such tailor-made campaigns 
might be a cost-effective and, therefore, long-term possibility to enhance early treatment of one of the most costly disorders, i.e. psychosis.

Acknowledgments The study was funded by the German Federal Ministry of Education and Research (Grant 01 GI 0235 to Prof. J. Klosterkötter, Cologne, and Prof. W. Maier, Bonn). Data assessments were supported by Daniel Köhn, Heinz Picker, Sarah von der Laage, Annett Nüchter, all formerly Cologne; Verena Pützfeld, Cologne; Julia Berning, Julia Bludau, both formerly Bonn, and Antje Niedersteberg, formerly Duisburg.

Conflict of interest All authors declare no conflict of interest in relation to the present study.

\section{References}

1. Wittchen HU, Jacobi F, Rehm J et al (2011) The size and burden of mental disorders and other disorders of the brain in Europe 2010. Eur Neuropsychopharmacol 21:655-679

2. Penttilä M, Jääskeläinen E, Hirvonen N, Isohanni M, Miettunen J (2014) Duration of untreated psychosis as predictor of long-term outcome in schizophrenia: systematic review and meta-analysis. Br J Psychiatry 205:88-94

3. Norman RM, Manchanda R, Windell D, Harricharan R, Northcott S, Hassall L (2012) The role of treatment delay in predicting 5 -year outcomes in an early intervention program. Psychol Med 42:223-333

4. Marshall M, Lewis S, Lockwood A, Drake R, Jones P, Croudace $T$ (2005) Association between duration of untreated psychosis and outcome in cohorts of first-episode patients: a systematic review. Arch Gen Psychiatry 62:975-983

5. Keshavan MS, Haas G, Miewald J et al (2003) Prolonged untreated illness duration from prodromal onset predicts outcome in first episode psychoses. Schizophr Bull 29:757-769

6. Schimmelmann BG, Huber CG, Lambert M, Cotton S, McGorry PD, Conus P (2008) Impact of duration of untreated psychosis on pre-treatment, baseline, and outcome characteristics in an epidemiological first-episode psychosis cohort. J Psychiatr Res 42:982-990

7. Schimmelmann BG, Conus P, Cotton S, McGorry PD (2007) Pretreatment, baseline, and outcome differences between early-onset and adult-onset psychosis in an epidemiological cohort of 636 first-episode patients. Schizophr Res 95:1-8

8. Marshall M, Husain N, Bork N et al (2014) Impact of early intervention services on duration of untreated psychosis: data from the National EDEN prospective cohort study. Schizophr Res 159:1-6

9. Schultze-Lutter F, Michel C, Schmidt SJ et al (2015) EPA guidance on the early detection of clinical high risk states of psychoses. Eur Psychiatry 30:405-416

10. Schaffner N, Schimmelmann BG, Niedersteberg A, SchultzeLutter F (2012) Pathways-to-Care for First-Episode psychotic patients-an overview of international studies. Fortschr Neurol Psychiatr 80:72-78

11. Archie S, Akhtar-Danesh N, Norman R, Malla A, Roy P, Zipursky RB (2010) Ethnic diversity and pathways to care for a first episode of psychosis in Ontario. Schizophr Bull 36:688-701

12. Cheung D, Roper L, Purdon SE (2014) Pathways to (specialized) care: patient costs and contacts en route to a first-episode psychosis clinic. Early Interv Psychiatry 8:375-381

13. O'Callaghan E, Turner N, Renwick L et al (2010) First episode psychosis and the trail to secondary care: help-seeking and health-system delays. Soc Psychiatry Psychiatr Epidemiol 45:381-391

14. Chung YC, Jung HY, Kim SW et al (2010) What factors are related to delayed treatment in individuals at high risk for psychosis? Early Interv Psychiatry 4:124-131

15. Cocchi A, Meneghelli A, Erlicher A, Pisano A, Cascio MT, Preti A (2013) Patterns of referral in first-episode schizophrenia and ultra high-risk individuals: results from an early intervention program in Italy. Soc Psychiatry Psychiatr Epidemiol 48:1905-1916

16. Fridgen GJ, Aston J, Gschwandtner U et al (2013) Help-seeking and pathways to care in the early stages of psychosis. Soc Psychiatry Psychiatr Epidemiol 48:1033-1043

17. Platz C, Umbricht DS, Cattapan-Ludewig K et al (2006) Helpseeking pathways in early psychosis. Soc Psychiatry Psychiatr Epidemiol 41:967-974

18. Shin YM, Jung HY, Kim SW et al (2010) A descriptive study of pathways to care of high risk for psychosis adolescents in Korea. Early Interv Psychiatry 4:119-123

19. Stowkowy J, Colijn MA, Addington J (2013) Pathways to care for those at clinical high risk of developing psychosis. Early Interv Psychiatry 7:80-83

20. Von Reventlow HG, Krüger-Özgürdal S, Ruhrmann $S$ et al (2014) Pathways to care in subjects at high risk for psychotic disorders-a European perspective. Schizophr Res 152:400-407

21. Wiltink S, Velthorst E, Nelson B, McGorry PM, Yung AR (2015) Declining transition rates to psychosis: the contribution of potential changes in referral pathways to an ultra-high-risk service. Early Interv Psychiatry 9:200-206

22. Häfner H, Maurer K, Ruhrmann S et al (2004) Early detection and secondary prevention of psychosis: facts and visions. Eur Arch Psychiatry Clin Neurosc 254:117-128

23. Schultze-Lutter F, Ruhrmann S, Berning J, Maier W, Klosterkötter J (2010) Basic symptoms and ultrahigh risk criteria: symptom development in the initial prodromal state. Schizophr Bull 36:182-191

24. Maurer K, Horrmann F, Trendler G, Schmidt M, Häfner H (2006) Früherkennung des Psychoserisikos mit dem Early Recognition Inventory (ERIraos). Beschreibung des Verfahrens und erste Ergebnisse zur Reliabilitat und Validitat der Checkliste. Nervenheilkunde 1-2:11-16

25. Maurer K, Häfner H (1995) Methodological aspects of the onset assessment in schizophrenia. Schizophr Res 15:265-276

26. Klosterkötter J, Hellmich M, Steinmeyer EM, Schultze-Lutter F (2001) Diagnosing schizophrenia in the initial prodromal phase. Arch Gen Psychiatry 58:158-164

27. Yung AR, Phillips LJ, McGorry PD et al (1998) Prediction of psychosis. A step towards indicated prevention of schizophrenia. Br J Psychiatry Suppl 172:14-20

28. Gater R, Almeida Sousa de B, Barrientos G et al (1991) The pathways to psychiatric care: a cross-cultural study. Psychol Med 21:761-774

29. Schultze-Lutter F, Ruhrmann S, Schimmelmann BG, Michel C (2013) "A rose is a rose is a rose", but at-risk criteria differ. Psychopathology 46:75-87

30. Schimmelmann BG, Michel C, Schaffner N, Schultze-Lutter F (2011) What percentage of people in the general population satisfy the current clinical at-risk criteria of psychosis? Schizophr Res 125:99-100

31. Schultze-Lutter F, Klosterkötter J, Ruhrmann S (2014) Improving the clinical prediction of psychosis by combining ultra-high risk criteria and cognitive basic symptoms. Schizophr Res 154:100-106

32. Schultze-Lutter F, Resch F, Koch E, Schimmelmann BG (2011) Early detection of psychosis in children and adolescents-have developmental particularities been sufficiently considered? Z Kinder Jugendpsychiatr Psychother 39:301-311 
33. Yung AR, Stanford C, Cosgrave E, Killackey E, Phillips L, Nelson B, McGorry PD (2006) Testing the ultra high risk (prodromal) criteria for the prediction of psychosis in a clinical sample of young people. Schizophr Res 84:57-66

34. Mack S, Jacobi F, Gerschler A et al (2014) Self-reported utilization of mental health services in the adult German population-evidence for unmet needs? Results of the DEGS1-Mental Health Module (DEGS1-MH). Int J Methods Psychiatr Res 23:289-303

35. Schultze-Lutter F, Michel C, Ruhrmann S, Schimmelmann BG (2014) Prevalence of DSM-5 Attenuated Psychosis Syndrome in adolescents and young adults of the general population: the Bern Epidemiological At-Risk (BEAR) study. Schizophr Bull 40:1499-1508

36. Friis S, Melle I, Larsen TK et al (2004) Does duration of untreated psychosis bias study samples of first-episode psychosis? Acta Psychiatr Scand 110:286-291

37. Schimmelmann BG, Michel C, Martz-Irngartinger A, Linder C, Schultze-Lutter F (2015) Age matters in the prevalence and clinical significance of ultra-high-risk for psychosis symptoms and criteria in the general population: findings from the BEAR and BEARS-Kid studies. World Psychiatry 14:189-197

38. Harris MG, Henry LP, Harrigan SM et al (2005) The relationship between duration of untreated psychosis and outcome: an eightyear prospective study. Schizophr Res 79:85-93

39. Harrigan SM, McGorry PD, Krstev H (2003) Does treatment delay in first-episode psychosis really matter? Psychol Med 33:97-110

40. Joa I, Johannessen JO, Langeveld J et al (2009) Baseline profiles of adolescent vs. adult-onset first-episode psychosis in an early detection program. Acta Psychiatr Scand 119:494-500

41. Anderson KK, Fuhrer R, Malla AK (2013) "There are too many steps before you get to where you need to be": help-seeking by patients with first-episode psychosis. J Ment Health 22:384-395

42. Boydell KM, Volpe T, Gladstone BM, Stasiulis E, Addington J (2013) Youth at ultra high risk for psychosis: using the Revised
Network Episode Model to examine pathways to mental health care. Early Interv Psychiatry 7:170-186

43. Johannessen JO, McGlashan TH, Larsen TK et al (2001) Early detection strategies for untreated first-episode psychosis. Schizophr Res 51:39-46

44. Johannessen JO, Friis S, Joa I et al (2007) First-episode psychosis patients recruited into treatment via early detection teams versus ordinary pathways: course, outcome and health service use during first 2 years. Early Interv Psychiatry 1:40-48

45. Fuchs J, Steinert T (2002) Inanspruchnahme professioneller Hilfe, Einweisungswege und Dauer der unbehandelten Psychose bei erstmals stationär aufgenommenen Patienten. Fortschr Neurol Psychiatr 70:40-45

46. Fuchs J, Steinert T (2004) Patients with first episode of schizophrenia spectrum psychosis and their pathways to psychiatric hospital care in South Germany. Soc Psychiatry Psychiatr Epidemiol 39:375-380

47. Köhn D, Pukrop R, Niedersteberg A et al (2004) Wege in die Behandlung: Hilfesuchverhalten schizophrener Ersterkrankter. Fortschr Neurol Psychiatr 72:1-8

48. Köhn D, Niedersteberg A, Wieneke A et al (2004) Frühverlauf schizophrener Ersterkrankungen mit langer Dauer der unbehandelten Erkrankung. Fortschr Neurol Psychiatr 72:88-92

49. Delnoij DM (2013) Bismarck or Beveridge: primary care matters. Eur J Public Health 23:349

50. Lameire N, Joffe P, Wiedemann M (1999) Healthcare systems-an international review: an overview. Nephrol Dial Transplant 14:3-9

51. Reynolds N, Wuyts P, Badger S, Fusar-Poli P, McGuire P, Valmaggia L (2014) The impact of delivering GP training on the clinical high risk and first-episode psychosis on referrals and pathways to care. Early Interv Psychiatry. doi:10.1111/eip.12126 